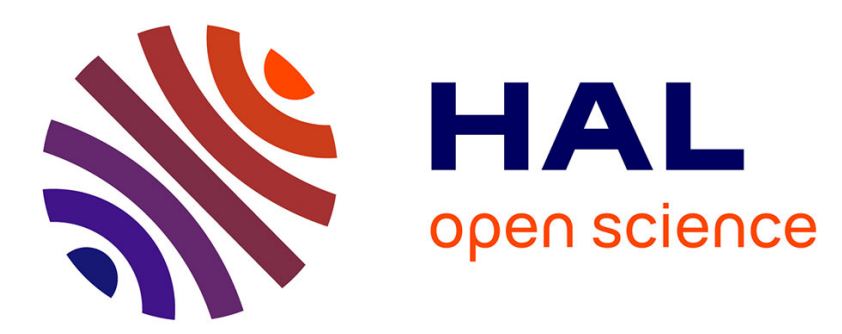

\title{
The essential role of charge-shift bonding in hypervalent prototype XeF2
}

Benoît Braïda, Philippe C. Hiberty

\section{To cite this version:}

Benoît Braïda, Philippe C. Hiberty. The essential role of charge-shift bonding in hypervalent prototype XeF2. Nature Chemistry, 2013, 5 (5), pp.417-422. 10.1038/nchem.1619 . hal-01627883

\section{HAL Id: hal-01627883 \\ https://hal.science/hal-01627883}

Submitted on 9 Nov 2017

HAL is a multi-disciplinary open access archive for the deposit and dissemination of scientific research documents, whether they are published or not. The documents may come from teaching and research institutions in France or abroad, or from public or private research centers.
L'archive ouverte pluridisciplinaire $\mathbf{H A L}$, est destinée au dépôt et à la diffusion de documents scientifiques de niveau recherche, publiés ou non, émanant des établissements d'enseignement et de recherche français ou étrangers, des laboratoires publics ou privés. 


\title{
The essential role of charge-shift bonding in hypervalent prototype $\mathrm{XeF}_{2}$
}

\author{
Benoît Braïda ${ }^{1 \star}$ and Philippe C. Hiberty ${ }^{2 \star}$
}

\begin{abstract}
Hypervalency in $\mathrm{XeF}_{2}$ and isoelectronic complexes is generally understood in terms of the Rundle-Pimentel model (which invokes a three-centre/four-electron molecular system) or its valence bond version as proposed by Coulson, which replaced the old expanded octet model of Pauling. However, the Rundle-Pimentel model is not always successful in describing such complexes and has been shown to be oversimplified. Here using ab initio valence bond theory coupled to quantum Monte Carlo methods, we show that the Rundle-Pimentel model is insufficient by itself in accounting for the great stability of $\mathrm{XeF}_{2}$, and that charge-shift bonding, wherein the large covalent-ionic interaction energy has the dominant role, is a major stabilizing factor. The energetic contribution of the old expanded octet model is also quantified and shown to be marginal. Generalizing to isoelectronic systems such as $\mathrm{CIF}_{3}, \mathrm{SF}_{4}, \mathrm{PCl}_{5}$ and others, it is suggested that charge-shift bonding is necessary, in association with the Rundle-Pimentel model, for hypervalent analogues of $X F_{2}$ to be strongly bonded.
\end{abstract}

$\mathrm{N}$ oble gas-containing compounds were long considered unstable because of their violation of the octet rule. However, they began to attract a lot of attention soon after the discovery of $\mathrm{XePtF}_{6}$ by Bartlett ${ }^{1}$, which was shortly followed by the synthesis of $\mathrm{XeF}_{2}$ (ref. 2). This latter compound, the smallest product of noble gas chemistry, is also the prototype for a wide category of isoelectronic hypervalent molecules such as $\mathrm{XeCl}_{2}, \mathrm{KrF}_{2}$, $\mathrm{RnF}_{2}, \mathrm{ClF}_{3}, \mathrm{SF}_{4}$ and $\mathrm{PCl}_{5}$, among others. It is therefore of primary importance to fully understand the nature of bonding in this prototype molecule.

The first tentative explanation for the hypervalency of $\mathrm{P}$ and $\mathrm{S}$ atoms was proposed by Pauling in terms of an expanded octet model, through promotion of electrons into vacant high-lying $d$ orbitals, leading to $s p^{3} d$ hybridization ${ }^{3}$. However, it has been shown by many researchers ${ }^{4-9}$ that, even if $d$ orbitals are necessary to provide quantitative bond energies in hypervalent species, these orbitals have occupancies of only 0.3 electrons at most ${ }^{10}$, and therefore do not act primarily as valence orbitals but instead as polarization functions or as acceptor orbitals for back-donation from the ligands. Accordingly, the energetic contributions of $s p^{3} d$ hybridization to hypervalent bonding are expected to be small (amazingly, to our knowledge, such quantities have never been estimated, even approximately).

It was soon realized that the explanation for hypervalency needed an alternative to the expanded octet model. In 1951, Pimentel and Rundle presented a simple and lucid model of hypervalency that does not require $d$-orbital participation ${ }^{11,12}$. The model is based on a general three-centre-four-electron $(3 c-4 e)$ molecular system, comprising three atoms or fragments that each contribute a single atomic orbital, from which one can construct a set of three molecular orbitals (MOs) of bonding, non-bonding and antibonding character, respectively. In the case of $\mathrm{XeF}_{2}$, three pure $p_{z}$ orbitals (or $s$ orbitals in the $\mathrm{H}_{3}{ }^{-}$case) combine to form the set of MOs $\varphi_{1}-\varphi_{3}$ (Fig. 1), of which only the first two are occupied, giving a net bond order of 0.5 . The Rundle-Pimentel model was immediately accepted by a wide number of chemists and served to rationalize and predict many structures.
However, Hoffmann and colleagues showed, in a systematic theoretical study of electron-rich $\mathrm{X}_{3}$ systems, that the simple RundlePimentel model is oversimplified, as it does not take $s, p$ orbital mixing into account ${ }^{13}$. As this $s, p$ mixing gives some antibonding character to the $\varphi_{2}$ MO in Fig. 1, some 3c-4e systems become unstable when this mixing is strong. However, even this addition to the Rundle-Pimentel model fails to explain why the simplest $3 \mathrm{c}-4 \mathrm{e}$ system, the $\mathrm{H}_{3}{ }^{-}$anion, is unstable, but isoelectronic $\mathrm{F}_{3}{ }^{-}$is stable. Clearly then, for the Rundle-Pimentel model to be entirely successful, there must be other factors yet to be taken into account.

One variant of the Rundle-Pimentel model is the resonance valence bond (VB) model, proposed by Coulson ${ }^{14}$. In this model, the electronic structure of $\mathrm{XeF}_{2}$ is described as a resonating combination of a few VB structures:

$$
\mathrm{XeF}_{2}=\mathrm{F} \bullet-\bullet \mathrm{Xe}^{+} \mathrm{F}^{-} \leftrightarrow \mathrm{F}^{-} \mathrm{Xe}^{+} \bullet-\bullet \mathrm{F} \leftrightarrow \mathrm{F}^{-} \mathrm{Xe}^{2+} \mathrm{F}^{-}
$$

where the first two VB structures display a covalent bond between one fluorine atom and a central Xe cation ('•' symbolizes a single electron), while the third structure is fully ionic. This model clearly shows that an electron must be transferred from the central atom to the ligands for hypervalency to take place. This stresses the importance of a low ionization potential for the central atom, associated with a strong electron affinity of the ligands.

Coulson demonstrated the close connection between the $3 \mathrm{c}-4 \mathrm{e}$ MO model and the VB resonance model ${ }^{14}$ by expanding the singledeterminant $\mathrm{MO}$ wavefunction in terms of atomic-orbital determinants, which are then regrouped as VB structures (Supplementary Section S1). The result of the transformation (equation (2)), shows that the MO wavefunction is equivalent to a six-structure VB function.

$$
\begin{aligned}
\Psi\left(\varphi_{\mathrm{I}}^{2} \varphi_{2}^{2}\right)= & \mathrm{F} \bullet-\bullet \mathrm{Xe}^{+} \mathrm{F}^{-}+\mathrm{F}^{-} \mathrm{Xe}^{+} \bullet-\bullet \mathrm{F}+\mathrm{F}^{-} \mathrm{Xe}^{2+} \mathrm{F}^{-} \\
& +1 / 2\left[\mathrm{~F}^{-} \mathrm{XeF}^{+}+\mathrm{F}^{+} \mathrm{XeF}^{-}+\sqrt{2} \bullet \mathrm{FXeF} \bullet\right]
\end{aligned}
$$

Even if, as we shall see, the coefficients of the three last structures are largely overestimated in the MO-VB expansion, the connection

'UPMC Université Paris 06, CNRS UMR 7616, Laboratoire de Chimie Théorique, C. 137, 4 Place Jussieu, 75252 Paris Cedex 05, France, ${ }^{2}$ Laboratoire de Chimie Physique, UMR CNRS 8000, Université de Paris Sud, 91405 Orsay Cédex, France. *e-mail: braida@lct.jussieu.fr; philippe.hiberty@u-psud.fr 


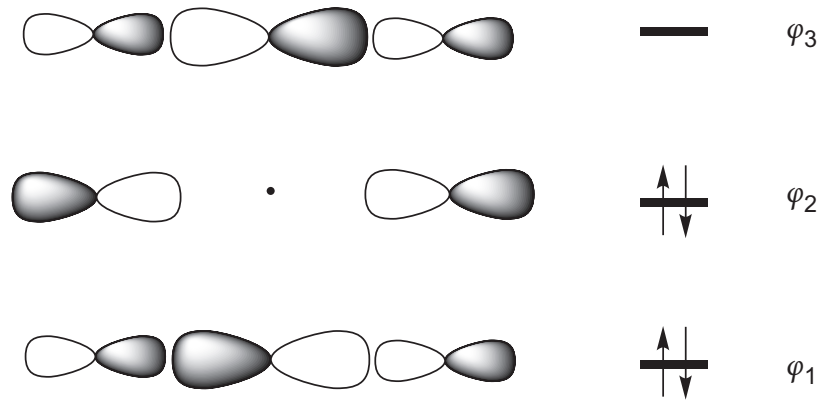

Figure 1 | The Rundle-Pimentel orbital model for 3c-4e hypervalent complexes. Each centre contributes a single atomic orbital from which one constructs three molecular orbitals, one each of bonding, non-bonding and antibonding character. Only the bonding and non-bonding orbitals are occupied, thus allowing the complex to be stable.

between the two models is still apparent, and all the more so as both explain hypervalency without the need for $d$-orbital participation.

The Coulson-Rundle-Pimentel (CRP) model therefore provides a plausible explanation for hypervalency of heavy noble gases, which have a low ionization potential, associated with light halogens, which are strongly electronegative. However, it still does not explain why $\mathrm{F}_{3}{ }^{-}$is stable but $\mathrm{H}_{3}{ }^{-}$is not. Moreover, the CRP model does not tell us anything about one important feature, the strength of the hypervalent bonds. Are they strong or weak? In fact, they can be amazingly strong, as in the $\mathrm{XeF}_{2}$ prototype, which has an atomization energy as large as $2.78 \mathrm{eV}\left(64.1 \mathrm{kcal} \mathrm{mol}^{-1}\right)^{15}$, quite a large value if one recalls that the octet rule would predict noble gases to be inert. The question becomes even more intriguing if one tries to estimate the stabilities of the VB structures in equation (1) relative to separate atoms, using experimentally known quantities ${ }^{16,17}$. For example, the bond dissociation energy $D_{0}$ of the two first VB structures, $\mathrm{F} \bullet-\bullet \mathrm{Xe}^{+} \mathrm{F}^{-}$or $\mathrm{F}^{-} \mathrm{Xe}^{+} \bullet-\bullet \mathrm{F}$, may be estimated by summing the reaction energies of the thermodynamic cycle (for details see Supplementary Section S2):

$$
\begin{gathered}
\mathrm{Xe} \rightarrow \mathrm{Xe}^{+} \quad \Delta E=12.13 \mathrm{eV}(\text { ref.16) } \\
\mathrm{F} \bullet \rightarrow \mathrm{F}^{-} \quad \Delta E=-3.40 \mathrm{eV}(\text { ref.16) } \\
\mathrm{Xe}^{+}+\mathrm{F} \bullet \rightarrow \mathrm{Xe}^{+} \bullet-\bullet \mathrm{F} \quad \text { Presumably } \Delta E>0 \\
\mathrm{~F}^{-}+\mathrm{Xe}^{+} \bullet-\bullet \mathrm{F} \rightarrow \mathrm{F}^{-} \mathrm{Xe}^{+} \bullet-\bullet \mathrm{F} \quad \Delta E>-7.28 \mathrm{eV}
\end{gathered}
$$

Note that the purely covalent bond (not the full bond) between $\mathrm{Xe}^{+}$ and $\mathrm{F}$ in equation (5) is assumed to be repulsive by analogy with the $\mathrm{F}_{2}$ covalent bond ${ }^{18,19}$, a hypothesis that will be verified in the following. Thus, summing equations (3) to (6) predicts the VB structures $\mathrm{F} \bullet-\bullet \mathrm{Xe}^{+} \mathrm{F}^{-}$and $\mathrm{F}^{-} \mathrm{Xe}^{+} \bullet-\bullet \mathrm{F}$ to be definitely unstable relative to $\mathrm{Xe}+2 \mathrm{~F} \bullet$, by at least $1.45 \mathrm{eV}\left(33.4 \mathrm{kcal} \mathrm{mol}^{-1}\right)$. A similar thermodynamic cycle would define the third (fully ionic) VB structure, $\mathrm{F}^{-} \mathrm{Xe}^{2+} \mathrm{F}^{-}$, as also largely unbound.

It follows that the large atomization energy of $\mathrm{XeF}_{2}$ cannot come from the bonding energies of any of the individual VB structures, but solely from an exceptionally large resonance energy arising from their mixing. Such bonds, in which the covalent-ionic resonance energy is the major cause for bonding, have been termed 'charge-shift bonds' 18,19 , and a typical example is found in the $\mathrm{F}_{2}$ molecule where both the covalent and ionic structures are individually unbound but their mixing provides a final bonding energy of $38.3 \mathrm{kcal} \mathrm{mol}^{-1}$ (ref. 20). A further clue suggestive of charge-shift bonding is that this bonding mode is often present when the bonded atoms bear lone pairs, which is the case in most hypervalent compounds with $\mathrm{S}, \mathrm{P}, \mathrm{Cl}$ or a noble gas as the central atom and halogens as ligands. Thus, as can be seen, there are some indications that charge-shift bonding might be an essential feature of hypervalency, and perhaps its root cause in many compounds. This prompted us to perform a thorough study of the nature of bonding in $\mathrm{XeF}_{2}$, as a prototype of many hypervalent compounds. This was done in the framework of the CRP model (equation(1)) using $a b$ initio VB methods.

\section{Results and discussion}

The present calculations use either the breathing-orbital VB method $(\mathrm{BOVB})^{21}$, or VB theory coupled to quantum Monte Carlo (QMC) methods ${ }^{22,23}$ (see Methods). Two levels of the VB-QMC method have been used: the VB-variational Monte Carlo method (VBVMC), which allows the calculation of diabatic energies for individual VB structures, and the VB-diffusion Monte Carlo method (VB-DMC), which lacks this latter capability but is more accurate regarding the multistructure ground state. A basis set of polarized triple-zeta quality is used throughout, with relativistic pseudopotentials, referred to as ps-VTZ.

Computational background. Since its synthesis ${ }^{2}$ in 1962, the $\mathrm{XeF}_{2}$ molecule has been the subject of a number of $a b$ initio theoretical studies $^{13,24-31}$. These studies show a consensus that electron correlation effects are essential ${ }^{25-30}$. A very accurate study was performed by Dixon and colleagues ${ }^{27}$ using a coupled-cluster $(\operatorname{CCSD}(\mathrm{T}))$ method with estimation of the complete basis set limit and corrections from core-valence excitations and relativistic effects. They found an atomization energy of $2.61 \mathrm{eV}\left(60.26 \mathrm{kcal} \mathrm{mol}^{-1}\right)$, close to experimental $D_{0}$ values ${ }^{16,32,33}$. They also computed a bonding energy $D_{\mathrm{e}}$ of $1.81 \mathrm{eV}\left(41.74 \mathrm{kcal} \mathrm{mol}^{-1}\right)$ for $\mathrm{XeF}^{+}$, again close to the experimental value of $1.95 \pm 0.16 \mathrm{eV}$ obtained from collision-induced dissociation studies ${ }^{34}$. $D_{\mathrm{e}}$ values can be obtained from $D_{0}$ values by adding a zero point energy of $2.16 \mathrm{kcal} \mathrm{mol}^{-1}$ for $\mathrm{XeF}_{2}$ and $0.92 \mathrm{kcal} \mathrm{mol}^{-1}$ for $\mathrm{XeF}^{+}$(ref. 27). However, the question of the nature of the bonds in these molecules is still open, hence our motivation to use VB theory to obtain more insight.

If one ignores the lone pairs of the $\mathrm{Xe}$ and $\mathrm{F}$ atoms, which play no direct role in axial bonds, $\mathrm{XeF}_{2}$ can be considered a $3 \mathrm{c}-4 \mathrm{e}$ system isoelectronic to $\mathrm{H}_{3}{ }^{-}$and isovalent to $\mathrm{F}_{3}{ }^{-}$. Now, recalling that $\mathrm{H}_{3}{ }^{-}$is an unstable transition state but $\mathrm{F}_{3}{ }^{-}$is stable $e^{35}$, it is interesting to note that the corresponding normal-valent compounds, $\mathrm{F}_{2}$ and $\mathrm{H}_{2}$, display correspondingly different bonding features: the $\mathrm{H}-\mathrm{H}$ bond is of the classical covalent type and the F-F bond is a typical charge-shift bond. Therefore, it appears to be of primary importance to study the $\mathrm{FXe}^{+}$normal-valent compound before studying $\mathrm{XeF}_{2}$.

The nature of the two-electron bond in normal-valent $\mathrm{F}-\mathrm{Xe}^{+}$. The VB description of $\mathrm{FXe}^{+}$involves three VB structures (Fig. 2). The weights of each structure are displayed below the corresponding cartoons, as calculated at the BOVB and VB-VMC levels. At both levels, structure $\mathbf{1}$ (which represents a purely covalent bond between $\mathrm{F}$ and $\mathrm{Xe}^{+}$) is the major one. Of the two ionic structures, $\mathbf{2}$ is the least important; and displays only one

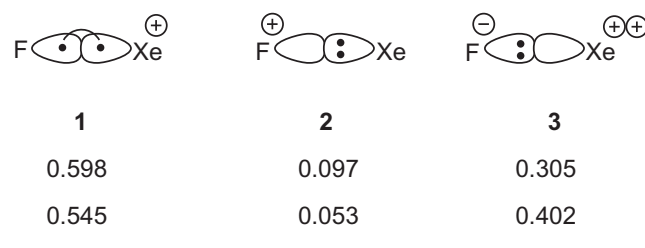

Figure 2 | The three VB structures of $\mathrm{F}-\mathrm{Xe}^{+}$and their weights as calculated by the BOVB (upper line) and VB-VMC (lower line) methods, in the ps-VTZ basis set. The hybridized atomic orbitals that are represented are mainly $p_{z}$ orbitals with some minor $s$ components and contributions of polarization functions. 
Table 1 | Energies of $\mathrm{F}-\mathrm{Xe}^{+}$relative to the separate atoms, and resonance energies arising from covalent-ionic mixing.

\begin{tabular}{lcccc} 
& $\begin{array}{l}\text { BOVB/ps-VTZ } \\
\left(\mathrm{kcal} \mathrm{mol}^{-1}\right)\end{array}$ & $\begin{array}{l}\text { VB-VMC/ps-VTZ } \\
\left(\mathrm{kcal} \mathrm{mol}^{-1}\right)\end{array}$ & $\begin{array}{l}\text { CCSD(T)/ps-VTZ } \\
\left(\mathrm{kcal} \mathrm{mol}^{-1}\right)\end{array}$ & $\begin{array}{l}\text { CCSD(T)/CBS } \\
\left(\mathrm{kcal} \mathrm{mol}^{-1}\right)\end{array}$ \\
\hline Structure 1 alone & 27.6 & 38.6 & - & - \\
Full ground state & -40.7 & -31.1 & -36.9 & -42.6 \\
$\mathrm{RE}^{\dagger}$ & 68.3 & 69.7 & - & - \\
\hline
\end{tabular}

${ }^{\star}$ For BOVB and VB-VMC calculations, this corresponds to the wavefunction including all structures 1-3.

TResonance energies (RE) due to mixing of $\mathbf{1}$ with $\mathbf{2}$ and $\mathbf{3}$.

From ref. 27.

ionized atom. In contrast, structure $\mathbf{3}$, in which the xenon atom is doubly ionized, has a remarkably large weight (0.31-0.40).

The importance of structure 3 is also revealed by the bonding energies of $\mathrm{FXe}^{+}$, as calculated with structure $\mathbf{1}$ alone or with the full set of structures 1-3 (Table 1). At both VB levels, covalent structure $\mathbf{1}$ is unbound, as expected from analogy with the $\mathrm{F}_{2}$ case. It therefore requires a considerable resonance energy, due to the mixing of structure $\mathbf{1}$ with ionic structures $\mathbf{2}$ and especially $\mathbf{3}$, to achieve a reasonable bonding energy $\left(41 \mathrm{kcal} \mathrm{mol}^{-1}\right.$ at the BOVB level versus $42.6 \mathrm{kcal} \mathrm{mol}^{-1}$ at the $\operatorname{CCSD}(\mathrm{T}) / \mathrm{CBS}_{\text {level}}{ }^{27}$ ). This resonance energy amounts to $68-70 \mathrm{kcal} \mathrm{mol}^{-1}$ and is thus significantly larger than the bonding energy itself. As such, the F-Xe ${ }^{+}$ bond is a typical charge-shift bond, owing all its bonding energy to a very large resonance energy due to covalent-ionic mixing.

The VB description of $\mathrm{XeF}_{2}$. The $\mathrm{VB}$ description of the active space of $\mathrm{XeF}_{2}$ involves the six $\mathrm{VB}$ structures of equation (2), from which we can eliminate $\mathrm{F}^{-} \mathrm{XeF}^{+}+\mathrm{F}^{+} \mathrm{XeF}^{-}$(presumably very high in energy). Now, for the sake of better elucidating the role of the $5 d_{z 2}$ orbitals of $\mathrm{Xe}$, we will split the four remaining VB structures into 4-7 (where the active electrons of $\mathrm{Xe}$ are in the axial $p_{z}$ orbital) and 8-11 (where at least one covalent bond involves the $5 d_{z 2}$ orbital of $\mathrm{Xe}$ ) with optimal contribution from $5 s$ components (called $5 d_{z 2}$ in the following). The combination of $\mathbf{4}$ and $\mathbf{8}$ (or 5 and 9) is therefore equivalent to a unique VB structure that displays a single bond to one $\mathrm{F}$ atom by means of a central orbital, which is a $p_{z}$ orbital polarized by the $5 d_{z 2}$ orbital. Structures $\mathbf{1 0}$ and $\mathbf{1 1}$ are fundamentally different. Each displays two Xe-F bonds and characterizes the direct participation of $5 d_{z 2}$ to bonding, following the $s p^{3} d$ hybridization scheme of Pauling ${ }^{3}$. Accordingly, the contribution of structures $\mathbf{1 0}$ and 11, in terms of weights or in terms of stabilization energy, is a direct measure of the importance of the expanded octet model.

The calculated relative energies of $\mathrm{XeF}_{2}$ with respect to its separate atoms are presented in Table 2. At the VB-VMC/ps-VTZ level, the calculated atomization energy is $48.7 \mathrm{kcal} \mathrm{mol}^{-1}$, better than the $\operatorname{CCSD}(\mathrm{T})$ value in the same basis set, but somewhat smaller than the experimental and CBS extrapolated values, reflecting the necessity of very large basis sets to obtain accurate energetics for this molecule. The VB-DMC level corrects for most of the remaining basis set deficiencies and correlation effects missing in the former wavefunction, and provides an atomization energy in excellent agreement

\section{Table 2 | Atomization energies of $\mathrm{XeF}_{2}$, as calculated by} VB-VMC, VB-DMC and CCSD(T) methods.

\begin{tabular}{ll} 
Computational method & Relative energy $\left(\mathrm{kcal} \mathrm{mol}^{-1}\right)^{\star}$ \\
\hline VB-VMC/ps-VTZ & 48.7 \\
CCSD $(T) /$ ps-VTZ & 40.1 \\
VB-DMC/ps-VTZ & 60.6 \\
CCSD (T)/CBS & 63.7 \\
Experiment & $62.2^{\dagger}, 63.4^{\$}$
\end{tabular}

*Energies relative to the separate atoms.

"Ref. 32.

Ref. 33. with the experimental value, showing that the set of VB structures 4-11 captures the essential physics of the ground state of $\mathrm{XeF}_{2}$.

How much does $s p^{3} d$ hybridization contribute to bonding in $\mathrm{XeF}_{2}$ ? The weights of structures $4-11$ of $\mathrm{XeF}_{2}$, as calculated at the VB-VMC/ps-VTZ level, are displayed in Fig. 3 (under their respective structures). It is apparent that the three VB structures of the Coulson-Rundle-Pimentel model (equation(1)) are largely dominant. These are covalent structures $\mathbf{4}+\mathbf{8}$ and $\mathbf{5}+\mathbf{9}$, and ionic structure $\mathbf{6}$, which together represent $81 \%$ of the electronic state. In contrast, diradical structure 7 has a weight of only 0.078 and may look amazingly marginal if one compares $\mathrm{XeF}_{2}$ to the $\pi$-system of ozone, another $3 \mathrm{c}-4 \mathrm{e}$ system, where the corresponding $\bullet \mathrm{O}-\mathrm{O}-\mathrm{O} \bullet$ structure predominates over $\mathrm{O}=\mathrm{O}^{+}-\mathrm{O}^{-}$(for an explanation see Supplementary Section S3). Finally, structures 10 and 11 together contribute only $11.2 \%$ to the wavefunction, thereby demonstrating the marginal contribution of $s p^{3} d$ hybridization. The stabilization energy contributed by structures $\mathbf{1 0}$ and $\mathbf{1 1}$ can also be estimated by comparing the atomization energies calculated with and without inclusion of $\mathbf{1 0}$ and $\mathbf{1 1}$ in the VB set.

Table 3 displays the energies of some individual VB structures (or combinations of them) for $\mathrm{XeF}_{2}$ relative to its separate atoms. A comparison of entries 5 and 6 shows that the effect of removing 10 and 11 from the wavefunction results in an energy increase of only $7.2 \mathrm{kcal} \mathrm{mol}^{-1}$, a value that can be considered a quantitative measure of the contribution of $s p^{3} d$ hybridization to the stability of $\mathrm{XeF}_{2}$.

What is the contribution of charge-shift bonding to the hypervalency of $\mathrm{XeF}_{2}$ ? The energies of the diabatic states, displayed in Table 3, can also be used to estimate the importance of resonance energies for the stability of $\mathrm{XeF}_{2}$. As has been stated, combination $(\mathbf{4}+\mathbf{8})$ represents the complete diabatic wavefunction for the covalent $\mathrm{VB}$ structure $\mathrm{F} \bullet-\bullet \mathrm{Xe}^{+} \mathrm{F}^{-}$, the first term of the CRP model in equation(1). As anticipated on the basis of experimental quantities, this VB structure is unbound, and so is ionic $\mathrm{VB}$ structure $\mathbf{6}$, or $\mathrm{F}^{-} \mathrm{Xe}^{2+} \mathrm{F}^{-}$, the third term in equation (1). On the other hand, the combination $4+5+8+9$ (entry 3 in Table 3 ) shows much lower energies than either $(\mathbf{4}+\mathbf{8})$ or $(5+9)$, by as much as $82.9 \mathrm{kcal} \mathrm{mol}^{-1}$, meaning that mixing the two covalent structures is exceptionally stabilizing. This deserves some comment.

Any symmetrical hypercoordinated species, say $\left[\mathrm{A}-\mathrm{B}-\mathrm{A}^{\prime}\right]$, can be considered as an intermediate or transition state in the exchange reaction $\mathrm{AB}+\mathrm{A}^{\prime} \rightarrow \mathrm{A}+\mathrm{BA}^{\prime}$, where $\mathrm{AB}$ and $\mathrm{BA}^{\prime}$ are normal-valent species. Generally, when $\mathrm{AB}$ is bound by a classical covalent bond, the so-called transition state resonance energy (TSRE) arising from mixing between the two $V B$ structures $A-B / A^{\prime}$ and $A / B-A^{\prime}$ in $\left[\mathrm{A}-\mathrm{B}-\mathrm{A}^{\prime}\right]$ is about one-half of the $\mathrm{AB}$ bonding energy or less ${ }^{36}$. However, much larger resonance energies can be found if $A B$ is bound by a charge-shift bond. For example, the TSRE is $41 \mathrm{kcal} \mathrm{mol}^{-1}$ in $\mathrm{H}_{3}^{-}$, less than half the bonding energy of $\mathrm{H}_{2}$, but it is $38.9 \mathrm{kcal} \mathrm{mol}^{-1}$ in $\mathrm{F}_{3}^{-}$, slightly larger than the bonding energy of $\mathrm{F}_{2}$ (ref. 35). Thus, a large TSRE in the hypercoordinated complex originates from the charge-shift character of the bond in 


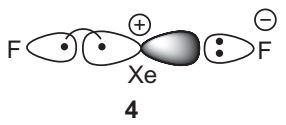

0.221

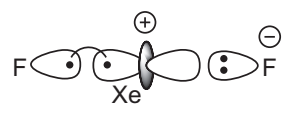

8

0.058

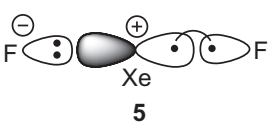

0.221

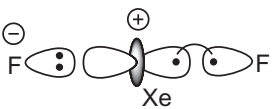

9

0.058

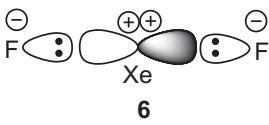

0.252

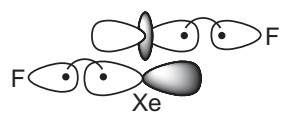

10

0.056

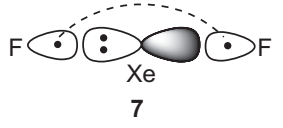

0.078

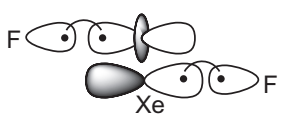

11

0.056

Figure 3 | VB structures of $\mathrm{XeF}_{2}$ and their weights, as calculated at the VB-VMC/ps-VTZ level. The central atomic orbital is a pure $5 p_{z}$ orbital in 4-7 and an optimized mixture of $5 \mathrm{~s}$ and $5 d_{z 2}$ in $\mathbf{8}$ and $\mathbf{9 . 1 0}$ and $\mathbf{1 1}$ each display two simultaneous covalent bonds, one by means of the $p_{z}$ atomic orbital and the other by means of the $5 s-5 d_{z 2}$ one. The set of structures $\mathbf{4 - 9}$ corresponds to the VB version of the Rundle-Pimentel model, in which the $d$ orbitals of Xe only have a role of polarization. Structures $\mathbf{1 0}$ and $\mathbf{1 1}$ characterize the $s p^{3} d$ expanded octet model.

the normal-valent compound. Where does $\mathrm{XeF}_{2}$ fit with respect to these two typical cases? Clearly, $\mathrm{XeF}_{2}$ falls on the same side as $\mathrm{F}_{3}{ }^{-}$, and even beyond, because the resonance energy between $\mathrm{F} \bullet-\bullet \mathrm{Xe}^{+} \mathrm{F}^{-}$and $\mathrm{F}^{-} \mathrm{Xe}^{+} \bullet-\bullet \mathrm{F}, 82.9 \mathrm{kcal} \mathrm{mol}^{-1}$, is about twice as large as the $\mathrm{F}-\mathrm{Xe}^{+}$bonding energy. This large resonance energy is connected to the charge-shift character of the $\mathrm{F}-\mathrm{Xe}^{+}$bond, and indeed this is already a strong argument in support of the role of charge-shift bonding in the stability of $\mathrm{XeF}_{2}$. However, this very large resonance energy is still insufficient to make $\mathrm{XeF}_{2}$ stable. About $18.6 \mathrm{kcal} \mathrm{mol}^{-1}$ can still be gained by adding diradical structure 7 , making the $\mathrm{XeF}_{2}$ complex nearly isoenergetic with the separate atoms. On the other hand, it is the covalent-ionic mixing, obtained by also adding structure $\mathbf{6}$, that definitely makes the system stable by contributing a resonance energy of $44.3 \mathrm{kcal} \mathrm{mol}^{-1}$ (entry 5 versus entry 4 in Table 3 ). At this level, $\mathrm{XeF}_{2}$ is stable by $41.5 \mathrm{kcal} \mathrm{mol}^{-1}$ relative to its separate atoms, close to the final value of $48.7 \mathrm{kcal} \mathrm{mol}^{-1}$ obtained by adding $s p^{3} d$ structures $\mathbf{1 0}$ and $\mathbf{1 1}$. Such systems, where stability is entirely due to covalent-ionic mixing, typically belong to the category of charge-shift-bonded molecules.

\section{Comparison with other rare-gas-fluorine complexes}

Coulson has already pointed out the importance of a low ionization potential for the central atom in compounds of the $\mathrm{XeF}_{2}$ type ${ }^{14}$. As a complement to Coulson's statement, our study emphasizes the contribution of the ionic structure $\mathrm{F}^{-} \mathrm{Xe}^{2+} \mathrm{F}^{-}$to the ground state of $\mathrm{XeF}_{2}$, and the concomitant necessity for a low second ionization potential for the central atom. This feature is also a necessary condition for chargeshift bonding to take place in $\mathrm{XeF}_{2}$, a property that can already be traced to the large resonance energy arising from the mixing of the $\mathrm{Xe}^{+} \bullet-\bullet \mathrm{F}$ and $\mathrm{Xe}^{2+} \mathrm{F}^{-}$structures in the normal-valent compound. For the sake of comparison, Table 4 reports the first and second ionization potentials of some rare gases $\mathrm{Rg}(\mathrm{Rg}=\mathrm{Ne}-\mathrm{Xe})$, the resonance energies in the $[\mathrm{RgF}]^{+}$normal-valent molecules, as well as the experimental atomization energies of $\mathrm{RgF}_{2}$. Not only does the rare-gas first ionization potential increase from Xe to $\mathrm{Ne}$, but the second ionization

Table 3 | Energies of some diabatic states of $\mathrm{XeF}_{2}$, as calculated at the VB-VMC/ps-VTZ level.

Set of VB structures

Relative energy $\left(\mathrm{kcal} \mathrm{mol}^{-1}\right)^{\star}$

$\mathbf{4 + 8}$ or $\mathbf{5 + 9} 104.3$

$4+5+8+9$

78.8

$4+5+7+8+9$

21.4

$4+5+6+7+8+9$

2.8

$4+5+6+7+8+9+10+11$

$-41.5$

$-48.7$

*Energies relative to the separate atoms.

\begin{tabular}{|c|c|c|c|c|}
\hline$[\mathrm{RgF}]^{+}$ & 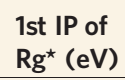 & $\begin{array}{l}\text { 2nd IP of } \\
\operatorname{Rg}^{\star}(e V)\end{array}$ & $\begin{array}{l}\mathrm{RE}^{\mathrm{t} \%} \text { of } \\
{[\mathrm{RgF}]^{+}(\mathrm{eV})}\end{array}$ & $\begin{array}{l}\text { Stability of } \\
\operatorname{RgF}_{2}(\mathrm{eV})\end{array}$ \\
\hline$\overline{[\mathrm{NeF}]^{+}}$ & 21.6 & 41.0 & 9.7 & Unstable \\
\hline$[\mathrm{ArF}]^{+}$ & 15.8 & 27.6 & 37.3 & Unstable \\
\hline$[\mathrm{KrF}]^{+}$ & 14.0 & 24.4 & 44.5 & $1.02^{5}$ \\
\hline$[\mathrm{XeF}]^{+}$ & 12.1 & 21.2 & 64.0 & $2.78^{\|}$ \\
\hline
\end{tabular}

${ }^{\star}$ Experimental values from Ref. 16 .

Defined as $R E=E\left(\mathrm{Rg}^{+} \bullet-\bullet \mathrm{F}\right)-E\left(\mathrm{Rg}^{+} \bullet-\bullet \mathrm{F} \leftrightarrow \mathrm{Rg}^{2+} \mathrm{F}^{-}\right)$

Calculated at the VB-VMC/ps-VTZ level.

${ }^{\text {s.Ref. }} 49$.

"Ref. 15.

potential increases even faster in the same series (up to $41.0 \mathrm{eV}$ for $\mathrm{Ne}$ ). Meanwhile, the resonance energies in $[\mathrm{RgF}]^{+}$gradually decrease from Xe to $\mathrm{Ne}$, finally being almost negligible in $[\mathrm{NeF}]^{+}$. Quite in harmony with these trends, $\mathrm{XeF}_{2}$ is strongly stable, $\mathrm{KrF}_{2}$ is weakly stable, and $\mathrm{ArF}_{2}$ and $\mathrm{NeF}_{2}$ are unstable.

\section{Conclusion and perspectives}

The $\mathrm{XeF}_{2}$ molecule, a classical prototype of hypervalent compounds, has been studied by using a VB-QMC method to gain detailed insight into the root causes for its amazing stability relative to its separate atoms. One side result of this study is a quantitative measure of the contribution of the old expanded octet model, which was thought long ago to explain hypervalency through $s p^{3} d$ hybridization. It is shown that the VB structures corresponding to this model account for $11.2 \%$ of the wavefunction, and bring a stabilization energy of only $7.2 \mathrm{kcal} \mathrm{mol}^{-1}$, much less than the total bonding energy. These results demonstrate, in a more quantitative way than has been done before, the definite superiority of the Rundle-Pimentel model over the expanded octet proposal.

In the $\mathrm{VB}$ framework, $\mathrm{XeF}_{2}$ is mainly described in terms of three VB structures, two covalent and one ionic, in accordance with the VB version of the Rundle-Pimentel model. However, none of these structures is bonding by itself, as they all lie much higher in energy than the dissociation limit. The mixing between the two covalent structures generates a resonance energy that is unexpectedly large $\left(82.9 \mathrm{kcal} \mathrm{mol}^{-1}\right)$. This large resonance energy in $\mathrm{XeF}_{2}$ arises from the charge-shift character of the corresponding normal-valent compound, $\mathrm{FXe}^{+}$, which displays a considerable covalent-ionic resonance energy, larger than the bonding energy itself, and therefore qualifies as a typical charge-shift bond. Thus, the charge-shift character of $\mathrm{FXe}^{+}$carries over to $\mathrm{XeF}_{2}$ and makes 
the combination of the covalent structures much lower in energy than either of them taken separately.

Another expression of charge-shift bonding in $\mathrm{XeF}_{2}$ can be seen in the large resonance energy $\left(44.3 \mathrm{kcal} \mathrm{mol}^{-1}\right)$ arising from the mixing of the ionic structure with the combination of covalent structures. This covalent-ionic resonance energy is close to the total bonding energy at this level of calculation, which is the very definition of a charge-shift-bonded system. Thus, charge-shift bonding is a key feature of hypervalency in $\mathrm{XeF}_{2}$, in agreement with an early proposal by Shaik ${ }^{37}$, and without the large resonance energies that are attached to this type of bonding the molecule would be unstable. This means that the complete explanation for the strong stability of $\mathrm{XeF}_{2}$ is a combination of the RundlePimentel model with the occurrence of charge-shift bonding. Incidentally, our model highlights the importance of the diionic structure $\mathrm{F}^{-} \mathrm{Xe}^{2+} \mathrm{F}^{-}$(often omitted in papers or textbooks), which must have a significant weight and, overall, be low enough in energy to efficiently mix with the $\mathrm{VB}$ structures $\mathrm{F} \bullet-\bullet \mathrm{Xe}^{+} \mathrm{F}^{-}$ and $\mathrm{F}^{-} \mathrm{Xe}^{+} \bullet-\bullet \mathrm{F}$. This necessity for a low second ionization potential reinforces the reason why $\mathrm{Ne}$ and Ar cannot be hypervalent, and why $\mathrm{XeF}_{2}$ has a greater atomization energy than $\mathrm{KrF}_{2}$.

Of course, the above discussed model is restricted to atoms that are prone to charge-shift bonding, that is, those from the right-hand side of the periodic table or bearing lone pairs, a necessary condition for charge-shift bonding to take place ${ }^{18,19}$. For atoms from the left-hand side, another hypervalency model already exists, the VB state correlation diagrams, published long ago by Shaik and colleagues ${ }^{38}$. However, the above model covers complexes of rare gas or isoelectronic groups, linked to electronegative atoms like halogens, and provides a simple explanation as to why some hypercoordinated species are stable but others are not. Thus, replacing $\mathrm{Xe}$ in $\mathrm{XeF}_{2}$ by isoelectronic groups such as $\mathrm{Kr}, \mathrm{Rn}, \mathrm{ClF}$ or $\mathrm{SF}_{2}$, one obtains $\mathrm{KrF}_{2}, \mathrm{RnF}_{2}, \mathrm{ClF}_{3}$ and $\mathrm{SF}_{4}$, while with the $\mathrm{PCl}_{3}$ fragment and $\mathrm{Cl}$ ligands one obtains $\mathrm{PCl}_{5}$, and so on; these are known hypervalent species in which we predict that charge-shift bonding is important. More $a b$ initio VB studies are on their way to confirming the latter predictions and to generalize the Rundle-Pimentel/charge-shift model of hypervalency.

\section{Methods}

A many-electron system wavefunction $\Psi$ in VB theory is expressed as a linear combination of Heitler-London-Slater-Pauling (HLSP) functions, $\Phi_{K}$ in equation (7):

$$
\Psi=\sum_{K} C_{K} \Phi_{K}
$$

where $\Phi_{K}$ corresponds to 'classical' VB structures and $C_{K}$ are structural coefficients. The weights of the VB structures are defined by the Coulson-Chirgwin formula ${ }^{39}$ (equation (8)), which is the equivalent of a Mulliken population analysis in VB theory:

$$
W_{K}=C_{K}^{2}+\sum_{L \neq K} C_{K} C_{L}\left\langle\Phi_{K} \mid \Phi_{L}\right\rangle
$$

where $\left\langle\Phi_{K} \mid \Phi_{L}\right\rangle$ is the overlap integral of two VB structures. An important feature of our VB calculations is that all the active orbitals, here the ones that are involved in the axial F-Xe bonds, are strictly localized on a single atom, as in the classical VB method, so as to ensure a clear correspondence between the mathematical expressions of the VB structures and their physical meaning, ionic or covalent.

There are several computational approaches for VB theory at the $a b$ initio level $^{40}$. In the VB self-consistent-field (VB-SCF) procedure ${ }^{41}$, both the VB orbitals and structural coefficients are optimized simultaneously to minimize the total energy. The $\mathrm{BOVB}^{21}$ method improves the accuracy of VB-SCF without increasing the number of VB structures $\Phi_{K}$. This is done by allowing each VB structure to have its own specific set of orbitals during the optimization process such that they can be different from one VB structure to the other. In this manner, the orbitals can fluctuate in size and shape so as to fit the instantaneous charges of the atoms on which these orbitals are located.

The BOVB method has several levels of sophistication ${ }^{21}$. Here we chose the 'SD-BOVB' level, whereby each doubly occupied active orbital is split into a pair of singly occupied orbitals accommodating a spin pair, so as to account for the radial correlation of the electrons involved in the lone pair. Moreover, in this option the orbitals that do not belong to the active space are allowed to delocalize. The BOVB calculations were carried out with the Xiamen Valence Bond (XMVB) program ${ }^{42-44}$.

Very recently, a mixed VB-QMC method was proposed that managed to provide high accuracy while keeping the full interpretative capabilities of classical VB methods ${ }^{22}$. In essence, the VB-QMC wavefunction we used consists of a VB-SCF determinant part multiplied by a Jastrow function, which is included to account for electronic correlation. In this study, the bond atomization energies were computed by optimizing Jastrow parameters, VB structures coefficients and all orbitals simultaneously, using the VMC optimization algorithm on the multistructure wavefunction and separate atoms, respectively. These VB-VMC wavefunctions are then projected onto the ground state using the DMC algorithm under the fixed-node approximation, a procedure that recovers most of the remaining correlation effects that are missing at the VB-VMC level, while at the same time compensating for basis set deficiencies, and usually provides very accurate energy differences ${ }^{22,23}$. This method is referred to here as VB-DMC. This latter method is more accurate for the ground state energy, but does not lend itself to the calculation of diabatic energies for individual VB structures, and cannot therefore be used for calculating resonance energies. For this purpose, VB-VMC must be used. For VB-VMC calculations of diabatic states, orbitals that are optimal for each separate combination of structures have been taken from an initial VB-SCF calculation, and then Jastrow parameters and VB structure coefficients are optimized at the VMC level. For all VB-QMC calculations, we used a systematically convergent triple-zeta polarized basis set from Burkatzki and colleagues $^{45}$, together with its corresponding pseudopotentials for both Xe and $\mathrm{F}$ atoms. (Basis sets and corresponding pseudopotentials are available online at http://burkatzki.com/pseudos/index.2.html.) For Xe and $\mathrm{Kr}$ atoms, to ensure enough flexibility for the $d$ shell set of basis functions, Burkatzki et al. TZP polarization functions were replaced by the $d$ set of basis functions taken from the cc-pvqz-PP basis set of Peterson and colleagues ${ }^{46}$. The so-constructed basis set is referred to as ps-VTZ in this work. All geometries were optimized at the $\operatorname{CCSD}(\mathrm{T})$ level using the latter basis sets with the GAUSSIAN09 program $^{47}$ (for details see Supplementary Information). All QMC calculations were carried out using the CHAMP program ${ }^{48}$.

\section{References}

1. Bartlett, N. Xenon hexafluoroplatinate (V) $\mathrm{Xe}^{+} \mathrm{PtF}_{6}^{-}$. Proc. Chem. Soc. Lond. 218 (1962).

2. Hope, R., Dähne, W., Rödder, K. M. \& Mattauch, H. Fluorierung von Xenon. Angew Chem. 74, 903 (1962).

3. Pauling, L. The Nature of the Chemical Bond 2nd edn, 145 (Cornell Univ. Press, 1940).

4. Rundle, R. E Probable structure of $\mathrm{XeF}_{4}$ and $\mathrm{XeF}_{2}$. J. Am. Chem. Soc. 85, 112-113 (1963)

5. Pitzer, K. S. Bonding in xenon fluorides and halogen fluorides. Science 139, 414 (1963).

6. Kutzelnigg, W. Chemical bonding in higher main group elements. Angew Chem. Int. Ed. 23, 272-295 (1984).

7. Malm, J. G., Selig, H., Jortner, J. \& Rice, S. A. The chemistry of xenon. Chem. Rev. 65, 199-236 (1965).

8. Reed, A. E. \& Schleyer, P. v. R. Chemical bonding in hypervalent molecules. The dominance of ionic bonding and negative hyperconjugation over $d$-orbital participation. J. Am. Chem. Soc. 112, 1434-1445 (1990).

9. Musher, J. I. The chemistry of hypervalent molecules. Angew. Chem. Int. Ed. 8, 54-68 (1969)

10. Reed, A. E. \& Weinhold, F. On the role of $d$ orbitals in $\mathrm{SF}_{6} . J$. Am. Chem. Soc. 108, 3586-3593 (1986).

11. Hach, R. J. \& Rundle, R. E. The structure of tetramethylammonium pentaiodide. J. Am. Chem. Soc. 73, 4321-4324 (1951).

12. Pimentel, G. C. The bonding of trihalide and bifluoride ions by the molecular orbital method. J. Chem. Phys. 19, 446-448 (1951).

13. Munzarova, M. L. \& Hoffmann, R. Electron-rich three-center bonding: role of $s, p$ interactions across the p-block. J. Am. Chem. Soc. 124, 4787-4795 (2002).

14. Coulson, C. A. The nature of the bonding in xenon fluorides and related molecules. J. Chem. Soc. 1442-1454 (1964).

15. Pepkin, V. I., Lebedev, Y. A. \& Apin, A. Y. Enthalpy of formation of xenon difluoride. Zh. Fiz. Khim. 43, 1564 (1969).

16. Weast, R. C. (ed.) Handbook of Chemistry and Physics 70th edn (CRC Press, 1989).

17. Bürger, H., Kuna, R., Ma, S., Breidung, J. \& Thiel, W. The vibrational spectra of krypton and xenon difuorides-high-resolution infrared studies and ab initio calculations. J. Chem. Phys. 101, 1-14 (1994).

18. Shaik, S., Danovich, D., Silvi, B., Lauvergnat, D. \& Hiberty, P. C. Charge-shift bonding - a class of electron-pair bonds that emerges from valence bond theory and is supported by the electron localization function approach. Chem. Eur. J. 11, 6358-6371 (2005) 
19. Shaik, S., Danovich, D., Wu, W. \& Hiberty, P. C. Charge-shift bonding and its manifestations in chemistry. Nature Chem. 1, 443-449 (2009).

20. Huber, K. P. \& Herzberg, G. Molecular Spectra and Molecular Structures Vol. 4 (van Nostrand Reinhold, 1979).

21. Hiberty, P. C. \& Shaik, S. Breathing-orbital valence bond method-a modern valence bond method that includes dynamic correlation. Theor. Chem. Acc. 108, 255-272 (2002).

22. Braida, B., Toulouse, J., Caffarel, M. \& Umrigar, C. J. Quantum Monte Carlo with Jastrow-valence-bond wave functions. J. Chem. Phys. 134, 084108 (2011).

23. Petruzielo, F. R., Toulouse, J. \& Umrigar, C. J. Approaching chemical accuracy with quantum Monte Carlo. J. Chem. Phys. 136, 124116 (2012).

24. Bagus, P. S., Liu, B., Liskow, D. H. \& Schaefer, H. F. Electron correlation and the reality of xenon difluoride. J. Am. Chem. Soc. 97, 7216-7219 (1975).

25. Styszynski, J., Cao, X., Mali, G. L. \& Visscher, L. Relativistic all-electron Dirac-Fock-Breit calculations on xenon fluorides $\left(\mathrm{XeF}_{n}, n=1,2,4,6\right)$. J. Comput. Chem. 18, 601-608 (1997).

26. Liao, M. S. \& Zhang, Q. E. Chemical bonding in $\mathrm{XeF}_{2}, \mathrm{XeF}_{4}, \mathrm{KrF}_{2}, \mathrm{KrF}_{4}, \mathrm{RnF}_{2}$, $\mathrm{XeCl}_{2}$, and $\mathrm{XeBr}_{2}$ : from the gas phase to the solid state. J. Phys. Chem. A 102, 10647-10654 (1998).

27. Dixon, D. A., de Jong, W. A., Peterson, K. A., Christe, K. O. \& Schrobilgen, G. Heats of formation of xenon fluorides and the fluxionality of $\mathrm{XeF}_{6}$ from high level electronic structure calculations. J. Am. Chem. Soc. 127, 8627-8634 (2005).

28. Haiduke, R. L. A., Filho, H. P. M. \& da Silva, A. B. F. A theoretical study on the $\mathrm{XeF}_{2}$ molecule. Chem. Phys. 348, 89-96 (2008).

29. Perpointner, M. \& Cederbaum, L. S. Effect of relativity on the ionization spectra of the xenon fluorides $\mathrm{XeF}_{n}(n=2,4,6)$. J. Chem. Phys. 122, 214302 (2005).

30. Kraupp, M., van Wüllen, Ch., Franke, R., Schmitz, F. \& Kutzelnigg, W. The Structure of $\mathrm{XeF}_{6}$ and of compounds isoelectronic with it. A challenge to computational chemistry and to the qualitative theory of the chemical bond. J. Am. Chem. Soc. 118, 11939-11950 (1996).

31. Kurzydlowski, D., Zaleski-Ejgierd, P., Grochala, W. \& Hoffmann, R. Freezing in resonance structures for better packing: $\mathrm{XeF}_{2}$ becomes $\left(\mathrm{XeF}^{+}\right)\left(\mathrm{F}^{-}\right)$at large compression. Inorg. Chem. 50, 3832-3840 (2011).

32. Weinstock, B., Weaver, E. E. \& Knop, C. P. The xenon-fluorine system. Inorg. Chem. 5, 2189-2203 (1966).

33. Berkowitz, J., Chupka, W. A., Guyon, P. M., Holloway, J. H. \& Spohr, R. Photoionization mass spectrometric study of $\mathrm{XeF}_{2}, \mathrm{XeF}_{4}$, and $\mathrm{XeF}_{6}$. J. Phys. Chem. 75, 1461-1471 (1971).

34. Krouse, I. H. \& Wenthold, P. G. Bond dissociation energy and Lewis acidity of the xenon fluoride cation. Inorg. Chem. 42, 4293-4298 (2003).

35. Braida, B. \& Hiberty, P. C. What makes the trifluoride anion $\mathrm{F}_{3}{ }^{-}$so special? A breathing-orbital valence bond $a b$ initio study. J. Am. Chem. Soc. 126, 14890-14898 (2004).

36. Shaik, S. \& Hiberty, P. C. A Chemist's Guide to Valence Bond Theory 142 (Wiley, 2008).

37. Shaik, S. S. in An Encomium to Linus Pauling. Molecules in Natural Science and Medicine (eds Maksic, Z. B. \& Maksic, M. E.) 253-266 (Ellis Horwood, 1991).
38. Shaik, S. \& Shurki, A. VB diagrams and chemical reactivity. Angew Chem. Int. Ed. 38, 586-625 (1999).

39. Chirgwin, H. B. \& Coulson, C. A. The electronic structure of conjugated systems. VI. Proc. R. Soc. Lond. A 201, 196-209 (1950).

40. Hiberty, P. C. \& Shaik, S. A survey of recent developments in ab initio valence bond theory. J. Comput. Chem. 28, 137-151 (2007).

41. van Lenthe, J. H. \& Balint-Kurti, G. G. The valence-bond self-consistent field method (VB-SCF): theory and test calculations. J. Chem. Phys. 78, 5699-5713 (1983)

42. Song, L., Wu, W., Mo, Y. \& Zhang, Q. XMVB: an ab initio non-orthogonal valence bond program (Xiamen University, 2003).

43. Song, L., Mo, Y., Zhang, Q. \& Wu, W. XMVB: a program for ab initio nonorthogonal valence bond computations. J. Comput. Chem. 26, 514-521 (2005).

44. Song, L., Song, J., Mo, Y. \& Wu, W. An efficient algorithm for energy gradients and orbital optimization in valence bond theory. J. Comput. Chem. 30, 399-406 (2009).

45. Burkatzki, M., Filippi, C. \& Dolg, M. Energy-consistent pseudopotentials for quantum Monte Carlo calculations. J. Chem. Phys. 126, 234105 (2007).

46. Peterson, K. A., Figgen, D., Goll, E., Stoll, H. \& Dolg, M. Systematically convergent basis sets with relativistic pseudopotentials. II. Small-core pseudopotentials and correlation consistent basis sets for the post- $d$ group 16-18 elements. J. Chem. Phys. 119, 11113-11123 (2003).

47. Frisch, M. J. et al. Gaussian 09, Revision A.02 (Gaussian, 2009).

48. Umrigar, C. J., Filippi, C. \& Toulouse, J. CHAMP, a Quantum Monte Carlo program ab initio program; available at http://pages.physics.cornell.edu/ cyrus/ champ.html

49. Bartlett, N. \& Sladky, F. O. Comprehensive Inorganic Chemistry Vol. 1 (eds Blair, J. C. \& Emeleus, H. J.) Ch. 6 (Pergamon, 1973).

\section{Acknowledgements}

The authors thank W. Wu and C.J. Umrigar for respectively making their XMVB and CHAMP code available to us.

\section{Author contributions}

Both authors designed the project. B.B. performed all the calculations. Both authors analysed the data. P.C.H. wrote the manuscript and the Supplementary Information. Both authors discussed the results and commented on the manuscript.

\section{Competing financial interests}

The authors declare no competing financial interests. 